\title{
A Study of Deformation Analysis Based on Non-equal Time Interval Grey Linear Combination Model
}

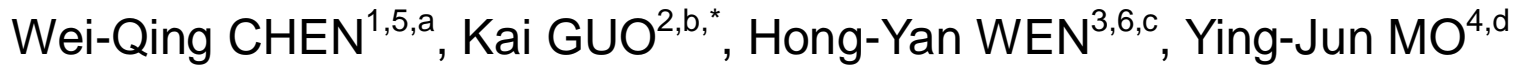 \\ ${ }^{1}$ Guangxi Key Laboratory of Disaster Prevention and Engineering Safety, Guangxi University, \\ Nanning 530004, China \\ ${ }^{2}$ Hohai University, Hohai University School of Earth Science and engineering, Nanjing 210000, \\ China \\ ${ }^{3}$ Guilin University of Technology, College of Surveying, Mapping and Geoinformation, Guilin 541004, \\ China \\ ${ }^{4}$ Guangxi Hydrogeology and Engineering Geology Exploration Institute, Liuzhou 454006, China \\ ${ }^{5}$ Guangxi University, College of Civil Engineering Architecture, Nanning 530004, China \\ ${ }^{6}$ Guangxi Key Laboratory for Spatial Information and Geometrics, Guilin 541004, China \\ agxcwq@163.com, bguokai4545@163.com, glitewhy@163.com, myj20082699@163.com \\ ${ }^{*}$ Corresponding author
}

Keywords: Deformation Analysis, Non-equal Time Interval, Grey System, Combination Model.

\begin{abstract}
Due to the scarcity of the characteristics of land resources, the number of ultra-high-rise building and underground engineering is becoming more and more in the town and its surrounding area, coupled with overexploitation and use of groundwater in some areas, the deformation of engineering and construction has presented situation of complex and volatile. Deformation monitoring of engineering construction, analysis and prediction of deformation have great significance for its safe use. Since the deformation of engineering and construction is a dynamic process of development, through the periodic deformation monitoring results can be found: changes in the pre-observation data contain a late development trend with inherent regularity. The non-equal time interval grey linear combination model is used in this paper to process some actual engineering data and compares with the traditional gray system data processing method. Finally, through the analysis of the above results, the features and benefits of this model has been analyzed and summarized.
\end{abstract}

\section{Introduction}

In the field of engineering and construction deformation data processing study, because the gray model has excellent applicability, and its composition is simple to understand, so it has been widely recognized by the academic community and the engineering department. The grey system theory is very different from methods of probability statistics and fuzzy mathematics, the theoretical essence of grey system modeling is to use part of the known information and try to discover the inherent variation characteristics of the deformation data by a certain way of grey generation, specifically, the grey model (GM) can be established by just more than four data through some transform generation [1] in the less information conditions. This modeling method overcomes the defect of statistical method which requires a huge number of sample data, and this has great practical significance for engineering analysis, prediction, decision-making and planning [2]. However, the specific grey modeling process is often complex, and difficult to meet the actual engineering operation requires, in contrast, the regression analysis is a traditional deformation analysis method, its modeling process of is simple, easy to use, and the effect of analysis is obvious to the data sequences with linear distribution. Combined with the advantages of the two modeling methods, the grey liner combination model is established according to the idea of the linear regression fitting with the grey model. After adding non-equal interval algorithm in this model, the combination model can be finally got, which is a few sample data required, higher short-term 
prediction accuracy and fully reflect the inherent characteristics of the sample data.

\section{The Basic Principle of Non-equal Time Interval Grey Linear Model}

\section{Construction of Grey Linear Model}

According to modeling principles GM $(1,1)$ model of grey model [3], Using sum of linear regression equation $Y=a X+b$ and exponential equation $Y=a e^{X}$ (a means Development factor, $\mathrm{b}$ means Gray action) to simulate gray linear model $[4,5]$ :

$$
\hat{x}^{(1)}(k)=C_{1} e^{v k}+C_{2} k+C_{3}
$$

In the formula above, $C_{1}, C_{2}, C_{3}, v$ need to estimate.

Consider the following functions

$$
\begin{aligned}
& L(k)=\hat{x}^{(1)}(k+1)-\hat{x}^{(1)}(k)=C_{1} e^{v k}\left(e^{v}-1\right)+C_{2} \\
& Y_{m}(k)=L(k+m)-L(k)=C_{1} e^{v k}\left(e^{v m}-1\right)\left(e^{v}-1\right)
\end{aligned}
$$

We can find:

$$
v=\ln \left[Y_{m}(k+1) / Y_{m}(k)\right]
$$

If accumulative sequence $x^{(1)}(k)$ instead of $\hat{x}^{(1)}(k)$, we can have an approximation $\tilde{V}$ to $v$, substitute into different $\mathrm{M}$ will get different $\tilde{V}$, take the average of all $\tilde{V}$ as $v$ :

$$
\widetilde{V}=\frac{\sum_{m=1}^{n-3} \sum_{k=1}^{n-2-m} v_{m}(k)}{(n-2)(n-3) / 2}
$$

According to (1), solved by the least squares method can get $C=\left(A^{T} A\right)^{-1} A^{T} \hat{X}^{(1)}$, among the equation:

$$
C=\left[\begin{array}{lll}
C_{1} & C_{2} & C_{3}
\end{array}\right]^{T} \quad A=\left[\begin{array}{ccc}
e^{v} & 1 & 1 \\
e^{2 v} & 2 & 1 \\
\cdots & \cdots & \cdots \\
e^{n v} & n & 1
\end{array}\right] \quad \hat{X}^{(1)}=\left[\begin{array}{c}
\hat{x}^{(1)}(1) \\
\hat{x}^{(1)}(2) \\
\ldots \\
\hat{x}^{(1)}(n)
\end{array}\right]
$$

Substitute into $C_{1}, C_{2}, C_{3}, v$, easy to get gray linear model

$$
\hat{x}^{(1)}(k)=C_{1} e^{v k}+C_{2} k+C_{3}
$$

According to $\hat{x}^{(0)}(k+1)=\hat{x}^{(1)}(k+1)-\hat{x}^{(1)}(k)$, regressive reduction of resulting sequence can get the value of the original model fit the data or the corresponding predicted values.

\section{Processing of Equal Interval of Non-equal Interval Sequence}

Both GM $(1,1)$ model and gray linear combination model are based on equal time intervals, in the actual deformation monitoring, periodic observation interval is typically unequal. So, in the beginning of building model, we should transform unequal time intervals settlement sequence to equal time intervals sequence $[6,7]$.

If original cumulative settling time sequence is: $\left\{x^{(0)}\left(t_{1}\right), x^{(0)}\left(t_{2}\right), \cdots, x^{(0)}\left(t_{k}\right)\right\},(k=1,2, \cdots, n)$.

The actual time interval is: $\Delta t_{k}=t_{k+1}-t_{k}$ 
The mean interval is:

$$
\Delta t_{0}=\frac{\sum_{k=1}^{n-1} \Delta t_{k}}{n-1}=\frac{\left(t_{n}-t_{1}\right)}{n-1} \quad(k=1,2, \cdots, n)
$$

The equal time intervals sequence is:

$$
z^{(0)}\left(t_{k}\right)=x^{(0)}\left(t_{k}\right)-\frac{t_{k}-(k-1) \Delta t_{0}}{\Delta t_{0}}\left[x^{(0)}\left(t_{k}\right)-x^{(0)}\left(t_{k-1}\right)\right]
$$

According to modeling principles of $\operatorname{GM}(1,1)$ model, modeling $\hat{z}^{(0)}(t)$ in equal time way, we can get response equation (9)and Grey linear combination model(10) of GM(1,1)model:

$$
\begin{aligned}
& \hat{z}^{(1)}(k+1)=\left(z^{(0)}(1)-\frac{b}{a}\right) e^{-a k}+\frac{b}{a} \\
& \hat{z}^{(1)}(k+1)=C_{1} e^{v(k+1)}+C_{2}(k+1)+C_{3}
\end{aligned}
$$

Restore as a function in relation to time $t$ ( $t$ means time interval from the first cycle), can get non-equal interval GM $(1,1)$ model response equation $(11)$ and non-equal time interval grey linear combination model (12):

$$
\begin{aligned}
& \hat{x}^{(1)}(t)=\left[x^{(0)}(1)-\frac{b}{a}\right] e^{-a t / \Delta t_{0}}+\frac{b}{a} \\
& \hat{x}^{(1)}(t)=C_{1} e^{v\left(t / \Delta t_{0}+1\right)}+C_{2}\left(t / \Delta t_{0}+1\right)+C_{3}
\end{aligned}
$$

Substitute prediction time $t$ into (13), can get deformation prediction values, The accuracy of testing methods of predictions are similar to equal time interval model:

$$
\left\{\begin{array}{c}
\hat{x}^{(0)}(t)=x^{(0)}(t), t=0 \\
\hat{x}^{(0)}(t)=\hat{x}^{(1)}(t)-\hat{x}^{(1)}\left(t-\Delta t_{0}\right), t>0
\end{array}\right.
$$

\section{The Case Analysis of Engineering Construction Deformation and Research Method}

The building NO.1 which belongs to the first phase of a certain construction project is frame structure and has 33 stories, this construction project was started in December 2007(the floor height is \pm 0.000 ), and the main body of the building was capped in June 2008, then it entered decoration and using stage. According to the settlement measurement requirements of the Code for Engineering Surveying (GB50026-2007) and the Code for deformation measurement of building structure(JGJ8-2007), ten observation points and three measurement reference points were embedded before. The settlement observation for this closed leveling line has been repeated 20 times on the basis of the second order leveling during the 15 months.

In Table 1, there are 13 observation results which have obvious linear features and the average settlements of every point listed, and then regard the first 8 observations as the measured data and the last 5 observations as predictions to analysis and research. We analyzed the features of the combination model for deformation data processing and analysis according to the comparison between the non-equal time interval grey linear combination model and single variable grey models. 
Tab.1 The Cumulative Settlement of Settlement Observation Points [mm]

\begin{tabular}{cccccccccccccc}
\hline \multirow{2}{*}{ Date } & Interva & Cumulativ & \multicolumn{4}{c}{ Cumulative Settlement of Observation Points } & \multicolumn{4}{c}{ Average } \\
& 1 Days & e Days & 1 & 2 & 3 & 4 & 5 & 6 & 7 & 8 & 9 & 10 & $\begin{array}{c}\text { Settlemen } \\
\text { t }\end{array}$ \\
\hline 2008.02 .13 & 0 & 0 & 0.8 & 0.8 & 0.8 & 0.8 & 0.8 & 0.7 & 0.7 & 1.0 & 0.9 & 0.8 & 0.81 \\
2008.02 .24 & 11 & 11 & 1.2 & 1.3 & 1.3 & 1.2 & 1.2 & 1.2 & 1.0 & 1.4 & 1.3 & 1.3 & 1.24 \\
2008.03 .05 & 9 & 20 & 1.5 & 1.7 & 1.7 & 1.6 & 1.7 & 1.6 & 1.4 & 1.8 & 1.8 & 1.8 & 1.66 \\
2008.03 .15 & 10 & 30 & 2 & 2.2 & 2.1 & 2 & 2.2 & 2.1 & 1.8 & 2.2 & 2.2 & 2.3 & 2.11 \\
2008.03 .24 & 9 & 39 & 2.5 & 2.7 & 2.6 & 2.4 & 2.6 & 2.5 & 2.3 & 2.6 & 2.7 & 2.8 & 2.57 \\
2008.04 .01 & 8 & 47 & 2.9 & 3.1 & 3.0 & 2.9 & 3.0 & 2.9 & 2.7 & 3.1 & 3.2 & 3.2 & 3.00 \\
2008.04 .10 & 9 & 56 & 3.5 & 3.7 & 3.6 & 3.5 & 3.5 & 3.4 & 3.3 & 3.5 & 3.6 & 3.7 & 3.53 \\
2008.04 .22 & 12 & 68 & 4.1 & 4.2 & 4.1 & 4.0 & 3.9 & 3.9 & 3.8 & 3.9 & 4.1 & 4.2 & 4.02 \\
2008.04 .30 & 8 & 76 & 4.7 & 4.7 & 4.7 & 4.6 & 4.4 & 4.4 & 4.4 & 4.4 & 4.6 & 4.8 & 4.57 \\
2008.05 .10 & 10 & 86 & 5.1 & 5.1 & 5.1 & 5.1 & 4.8 & 4.8 & 4.8 & 4.9 & 5.0 & 5.2 & 4.99 \\
2008.05 .20 & 10 & 96 & 5.5 & 5.5 & 5.6 & 5.5 & 5.2 & 5.2 & 5.2 & 5.4 & 5.5 & 5.6 & 5.42 \\
2008.05 .31 & 11 & 107 & 5.9 & 5.9 & 6.1 & 6.0 & 5.7 & 5.8 & 5.7 & 5.9 & 6.0 & 6.0 & 5.90 \\
2008.06 .13 & 13 & 120 & 6.5 & 6.5 & 6.6 & 6.5 & 6.2 & 6.4 & 6.2 & 6.3 & 6.5 & 6.4 & 6.41 \\
\hline
\end{tabular}

In Table 1, the first 8 measured data series is below:

$$
x^{(0)}\left(t_{k}\right)=\left\{x^{(0)}\left(t_{1}\right), x^{(0)}\left(t_{2}\right), \cdots, x^{(0)}\left(t_{8}\right)\right\}=\{0.81,1.24,1.66,2.11,2.57,3.00,3.53,4.02\} .
$$

To make the non-equal time interval series $x^{(0)}\left(t_{k}\right)$ to equal interval according to the formula (7) and (8) can get the average time interval $\Delta t_{0}$ and the equal time interval series $z^{(0)}\left(t_{k}\right)$ :

$$
\Delta t_{0}=9.7143, z^{(0)}\left(t_{k}\right)=\{0.81,1.1831,1.6353,2.0703,2.5632,3.0696,3.6547,4.02\} .
$$

After Building the difference equation $Y_{N}=B \hat{\alpha}$, the B and $Y_{N}$ can be got, and the developmental quotient $a$ and the actuating quantity $b$ in the grey model could be calculated with least square method: $a=-0.1821 b=1.1477$. Taking the above variables into the Whitening responsive formula (11), the grey model GM $(1,1)$ is as follow:

$$
\hat{x}^{(1)}(t)=7.1126 e^{0.1821\left(t / \Delta t_{0}\right)}-6.3026 .
$$

According to the method of grey liner combination building [8], coefficients $C_{1}, C_{2}, C_{3}, v_{\text {can be }}$ calculated and the results are as follow:

$$
C=\left[\begin{array}{l}
C_{1} \\
C_{2} \\
C_{3}
\end{array}\right]=\left[\begin{array}{c}
12953 \\
81 \\
-12953
\end{array}\right], \quad v=-0.0062 .
$$

After taking the above coefficients into the formula (12), the grey liner combination model of non-equal time interval is below:

$$
\hat{x}^{(1)}(t)=12953 e^{-0.0062\left(t / \Delta t_{0}+1\right)}+81\left(t / \Delta t_{0}+1\right)-12953 .
$$

Furthermore, in order to verify the universal effect of non-equal time interval grey linear combination model in this paper, in addition to the traditional GM $(1,1)$ model, we also joined the contrast with DGM $(1,1)$ which is short for Discrete Grey Model and can be interpreted as an improvement on $\operatorname{GM}(1,1)$ model. DGM $(1,1)$ is an improved method which could overcome the continuity weakness of GM $(1,1)$ model and improve its fitting and prediction accuracy in some extent, the specific algorithm can reference [9], it will not be repeated here. 


\section{The Test Results Analysis and Discussion}

\section{Analysis of Model Fitting Effect}

The fitted values of the GM $(1,1)$ model and the grey liner combination model of non-equal time interval could be calculated by taking type(14), type(15) into type(13). Table 2 contains the fitted values and the residual errors of the first 8 observation data; Fig.1 is the comparison of fitting effect.

Tab. 2 The Fitted Results of the Three Models [mm]

\begin{tabular}{cccccccc}
\hline & & \multicolumn{2}{c}{$\mathrm{GM}(1,1)$} & \multicolumn{2}{c}{$\mathrm{DGM}(1,1)$} & \multicolumn{2}{c}{ Combination Model } \\
NO. & $\begin{array}{c}\text { Measured } \\
\text { data }\end{array}$ & $\begin{array}{c}\text { Fitted } \\
\text { Value }\end{array}$ & $\begin{array}{c}\text { Residual } \\
\text { Error }\end{array}$ & $\begin{array}{c}\text { Fitted } \\
\text { Value }\end{array}$ & $\begin{array}{c}\text { Residual } \\
\text { Error }\end{array}$ & $\begin{array}{c}\text { Fitted } \\
\text { Value }\end{array}$ & $\begin{array}{c}\text { Residual } \\
\text { Error }\end{array}$ \\
\hline 1 & 0.81 & 0.81 & 0 & 0.81 & 0 & 0.81 & 0 \\
2 & 1.24 & 1.4552 & -0.2152 & 1.4478 & -0.2078 & 1.1875 & 0.0525 \\
3 & 1.66 & 1.7227 & -0.0627 & 1.7273 & -0.0673 & 1.6466 & 0.0134 \\
4 & 2.11 & 2.0778 & 0.0322 & 2.0607 & 0.0493 & 2.1536 & -0.0436 \\
5 & 2.57 & 2.4597 & 0.1103 & 2.4585 & 0.1115 & 2.6071 & -0.0371 \\
6 & 3.00 & 2.8577 & 0.1423 & 2.933 & 0.067 & 3.0081 & -0.0081 \\
7 & 3.53 & 3.3828 & 0.1472 & 3.4992 & 0.0308 & 3.4567 & 0.0733 \\
8 & 4.02 & 4.2362 & -0.2162 & 4.1747 & -0.1547 & 4.0508 & -0.0308 \\
\hline
\end{tabular}

As can be seen from Fig. 1 that the proximity to the measured data of the combination model fitting trends is better than the traditional GM $(1,1)$ and its improved method DGM $(1,1)$, while the fitted results of the traditional GM $(1,1)$ model are more accord with the deformation tendency in the middle of several data, but the deviation data is large in the first and the last few cycles. GM (1, 1) and DGM $(1,1)$ are close to the fitting trend, it mainly because the parameter estimates is obtained when the development factor is relatively small in this measured data modeling, it illustrated that the difference between the continuous form and discrete form of whitenization equation is not big. Accordingly the combination model has obvious advantages in the analysis of the deformation data with a linear trend.

The fitting effect could be also analyzed according to the degree of accuracy and grade standard [10] in Table 3.Table 4 shows the accuracy class of the traditional GM $(1,1)$ and the combination mode $\cdots$

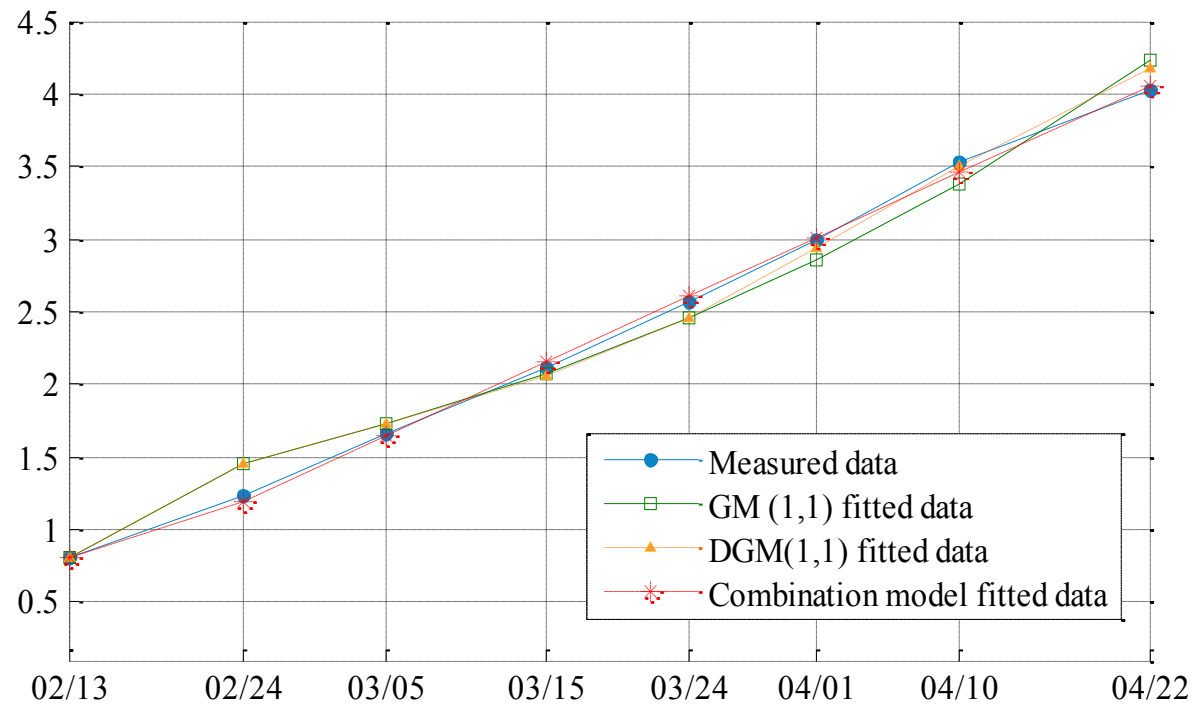

Fig. 1 The Comparison of Fitting Effect of Three Kinds of Models 
Tab. 3 The Degree of Accuracy and Grade Standard

\begin{tabular}{ccccc}
\hline & \multicolumn{2}{c}{ Accuracy Class } & \\
Accuracy Index & $\begin{array}{c}\text { First-Grad } \\
\text { e (Good) }\end{array}$ & $\begin{array}{c}\text { Second-Grade } \\
\text { (Qualified) }\end{array}$ & $\begin{array}{c}\text { Third-Grade } \\
\text { (Nearly Qualifie } \\
\text { d) }\end{array}$ & $\begin{array}{c}\text { Forth-Grade } \\
\text { (Unqualified) }\end{array}$ \\
\hline $\begin{array}{c}\text { Average Relative Error } \\
\bar{\varepsilon}\end{array}$ & $0.05>\bar{\varepsilon}$ & $0.05 \leq \bar{\varepsilon}<0.10$ & $0.10 \leq \bar{\varepsilon}<0.20$ & $\bar{\varepsilon}>0.20$ \\
$\begin{array}{c}\text { Posteriori Variance Ratio } \\
\text { C }\end{array}$ & $\mathrm{C}<0.35$ & $0.35 \leq \mathrm{C}<0.50$ & $0.50 \leq \mathrm{C}<0.65$ & $0.65 \leq \mathrm{C}$ \\
$\begin{array}{c}\text { Small Error Probability } \\
\mathrm{P}\end{array}$ & $0.95<\mathrm{P}$ & $0.80<\mathrm{P} \leq 0.95$ & $0.70<\mathrm{P} \leq 0.80$ & $\mathrm{P} \leq 0.70$ \\
\hline
\end{tabular}

Tab. 4 The Accuracy Class of the Three Models Fitting Results

\begin{tabular}{|c|c|c|c|c|c|c|}
\hline \multirow[b]{2}{*}{ Accuracy Index } & \multicolumn{2}{|c|}{$\operatorname{GM}(1,1)$} & \multicolumn{2}{|c|}{$\operatorname{DGM}(1,1)$} & \multicolumn{2}{|c|}{ Combination Model } \\
\hline & $\begin{array}{l}\text { Accuracy } \\
\text { Index }\end{array}$ & Accuracy Class & $\begin{array}{l}\text { Accuracy } \\
\text { Index }\end{array}$ & $\begin{array}{c}\text { Accuracy } \\
\text { Class }\end{array}$ & $\begin{array}{l}\text { Accuracy } \\
\text { Index }\end{array}$ & $\begin{array}{c}\text { Accuracy } \\
\text { Class }\end{array}$ \\
\hline Average Relative Error $\bar{\varepsilon}$ & 0.0515 & $\begin{array}{l}\text { Second-Grade } \\
\text { (Qualified) }\end{array}$ & 0.0430 & $\begin{array}{l}\text { First-Grade } \\
\text { (Good) }\end{array}$ & 0.0199 & $\begin{array}{c}\text { First-Grade } \\
\text { (Good) }\end{array}$ \\
\hline Posteriori Variance Ratio C & 0.1314 & $\begin{array}{l}\text { First-Grade } \\
\text { (Good) }\end{array}$ & 0.1002 & $\begin{array}{l}\text { First-Grade } \\
\text { (Good) }\end{array}$ & 0.0378 & $\begin{array}{l}\text { First-Grade } \\
\text { (Good) }\end{array}$ \\
\hline Small Error Probability $\quad \mathrm{P}$ & 1 & $\begin{array}{l}\text { First-Grade } \\
\text { (Good) }\end{array}$ & 1 & $\begin{array}{l}\text { First-Grade } \\
\text { (Good) }\end{array}$ & 1 & $\begin{array}{c}\text { First-Grade } \\
\text { (Good) }\end{array}$ \\
\hline
\end{tabular}

It can be seen from Table 4,except the Small Error Probability, the Average Relative Error and Posteriori Variance Ratio of the combination model are both better than the traditional GM $(1,1)$ and its improved method $\operatorname{DGM}(1,1)$, although posteriori variance ratio and the small error probability of GM $(1,1)$ has reached first-grade accuracy, its average relative error is only 0.0515 that is second-grade, and this is lower than the first-grade of the combination model which is 0.0199 ,so compared with $\operatorname{GM}(1,1)$, the combination model has obvious advantages in data fitting.

Tab. 5 the Prediction Results of the Three Models [mm]

\begin{tabular}{|c|c|c|c|c|c|c|c|}
\hline \multirow{2}{*}{ NO } & \multirow[b]{2}{*}{ Measured data } & \multicolumn{2}{|c|}{ GM(1,1) } & \multicolumn{2}{|c|}{$\operatorname{DGM}(1,1)$} & \multicolumn{2}{|c|}{ Combination Model } \\
\hline & & $\begin{array}{l}\text { Prediction } \\
\text { Value }\end{array}$ & $\begin{array}{l}\text { Residual } \\
\text { Error }\end{array}$ & $\begin{array}{l}\text { Prediction } \\
\text { Value }\end{array}$ & $\begin{array}{l}\text { Residual } \\
\text { Error }\end{array}$ & $\begin{array}{l}\text { Prediction } \\
\text { Value }\end{array}$ & $\begin{array}{c}\text { Residual } \\
\text { Error }\end{array}$ \\
\hline 9 & 4.57 & 4.9216 & -0.3516 & 4.9805 & -0.4105 & 4.4444 & 0.1256 \\
\hline 10 & 4.99 & 5.9363 & -0.9463 & 5.9419 & -0.9519 & 4.9335 & 0.0565 \\
\hline 11 & 5.42 & 7.1602 & -1.7402 & 7.0889 & -1.6689 & 5.4195 & 0.0005 \\
\hline 12 & 5.9 & 8.7999 & -2.8999 & 8.4573 & -2.5573 & 5.9505 & -0.0505 \\
\hline 13 & 6.41 & 11.2283 & -4.8183 & 10.0898 & -3.6798 & 6.5733 & -0.1633 \\
\hline
\end{tabular}

\section{Comparison of Prediction Results}

The next 5 cycles' data could be predicted by the three models and compared with the measured results, the prediction results are shown in Table 5, and Fig. 2 illustrates the comparison of prediction results.

It can be seen from Fig. 2 that the short-term prediction of $\operatorname{GM}(1,1)$ and $\operatorname{DGM}(1,1)$ are both good, which effect of discrete grey model $\operatorname{DGM}(1,1)$ is slightly better than the continuous model GM $(1,1)$, it mainly because the discrete grey model DGM $(1,1)$ has overcame the weakness of GM $(1,1)$ model from the theoretical point to some extent, in spite of this, their effect of long-term prediction are both poor. Compared with this situation, the non-equal time interval grey linear combination model can keep prediction accuracy well even in the long-term prediction conditions. Table 6 shows the prediction accuracy class of the three models.

It can be seen from Table 6 that the prediction accuracy of the non-equal time interval grey linear combination model is obviously better than the traditional GM $(1,1)$ and DGM $(1,1)$. The main 
reason is that the grey linear combination model has considered the inherent linear feature of the deformation data series, and this linear feature could be fitted by linear fitting method in some extent therefore the acrurary of the model hac heen oreatly imnroved

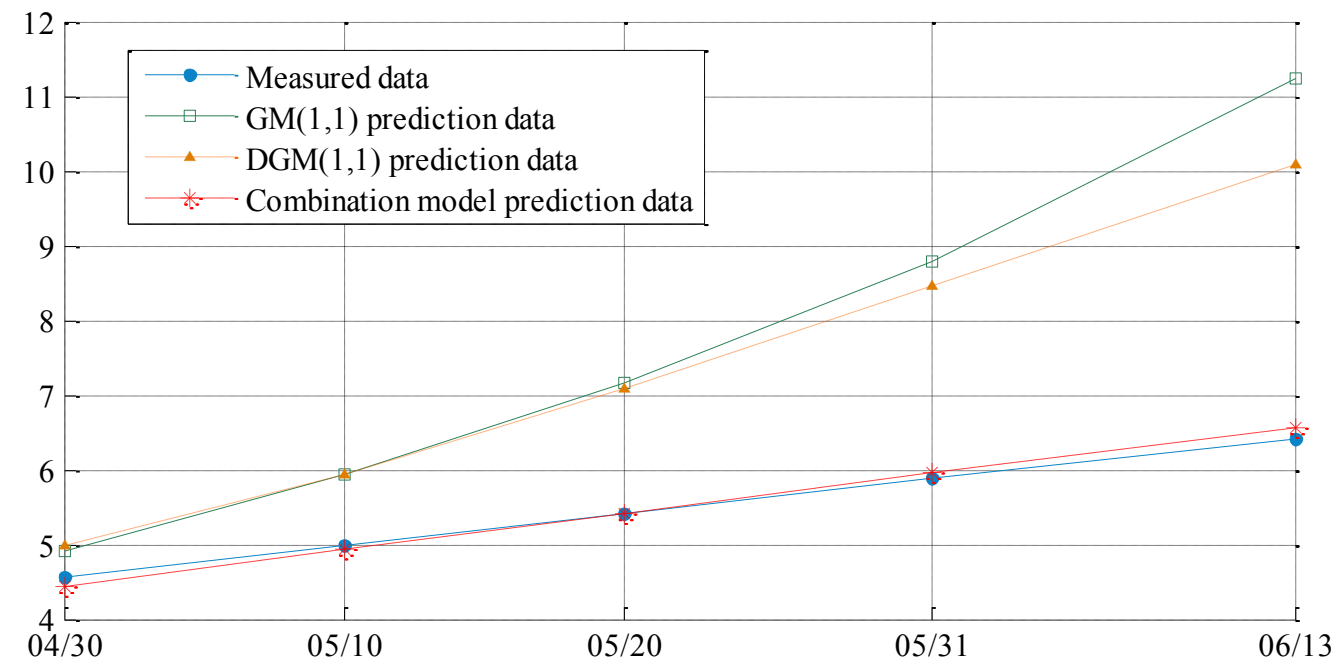

Fig. 2 The Comparison of Prediction Effect of Three Kinds of Models

Tab. 6 The Accuracy Class of the Three Models Prediction Results

\begin{tabular}{ccccccc}
\hline \multirow{2}{*}{ Accuracy Index } & \multicolumn{2}{c}{ GM(1,1) } & \multicolumn{2}{c}{ DGM(1,1) } & \multicolumn{2}{c}{ Combination Model } \\
\cline { 2 - 6 } & $\begin{array}{c}\text { Accurac } \\
\text { y Index }\end{array}$ & $\begin{array}{c}\text { Accuracy } \\
\text { Class }\end{array}$ & $\begin{array}{c}\text { Accurac } \\
\text { y Index }\end{array}$ & $\begin{array}{c}\text { Accuracy } \\
\text { Class }\end{array}$ & $\begin{array}{c}\text { Accurac } \\
\text { y Index }\end{array}$ & $\begin{array}{c}\text { Accuracy } \\
\text { Class }\end{array}$ \\
\hline $\begin{array}{c}\text { Average } \\
\begin{array}{c}\text { Relative Error } \\
\bar{\varepsilon}\end{array}\end{array}$ & 0.3662 & $\begin{array}{c}\text { Fourth-Grade } \\
\text { (Unqualified) }\end{array}$ & 0.3192 & $\begin{array}{c}\text { Fourth-Grade } \\
\text { (Unqualified) }\end{array}$ & 0.0146 & $\begin{array}{c}\text { First-Grade } \\
\text { (Good) }\end{array}$ \\
\hline $\begin{array}{c}\text { Posteriori Varian } \\
\text { ce Ratio C }\end{array}$ & 2.4368 & $\begin{array}{c}\text { Fourth-Grade } \\
\text { (Unqualified) }\end{array}$ & 1.7896 & $\begin{array}{l}\text { Fourth-Grade } \\
\text { (Unqualified) }\end{array}$ & 0.1508 & $\begin{array}{c}\text { First-Grade } \\
\text { (Good) }\end{array}$ \\
\hline $\begin{array}{c}\text { Small Error } \\
\text { Probability P }\end{array}$ & 0.2000 & $\begin{array}{c}\text { Fourth-Grade } \\
\text { (Unqualified) }\end{array}$ & 0.2000 & $\begin{array}{l}\text { Fourth-Grade } \\
\text { (Unqualified) }\end{array}$ & 1 & $\begin{array}{c}\text { First-Grade } \\
\text { (Good) }\end{array}$ \\
\hline
\end{tabular}

\section{Summary}

Since the grey system model could be established in the poor information conditions and overcome the defect of statistical method, it has been used widely in the engineering deformation analysis, prediction, decision-making and planning. However, the modeling process of the traditional GM (1, 1 ) is often complex and inconvenient for operation. Moreover its effect of analysis is not obvious to the data sequences with linear distribution because such model does not contain linear factors. Compared with traditional models, the Grey linear combination model combines the characteristics of linear regression and grey system and adds the linear factors based on the grey model. In some extent, the combination model overcomes the defect of traditional GM $(1,1)$, improves the accuracy of the model effectively, and is suitable for the analysis of deformation process with linear feature. After adding non-equal interval algorithm, The Practicability of Grey linear combination model has been further enhanced; it makes the combination model better applied to the fitting and the prediction of the non-equal time interval data series and improves the deformation analysis of application value in continuous time. Of course, in the analysis of building deformation, using the dynamic metabolism algorithm which constantly adds newinformation in grey data or measured data to establish dynamic model[11] can weaken grey plane further, so that it could improved the prediction accuracy of this combination model in a greater extent, and achieve better prediction effect. 


\section{Acknowledgement}

This research was financially supported by Guangxi Key Laboratory of disaster prevention and safety engineering (2013ZDX03). Project supported by the National Natural Science Foundation (41071294). Project supported by Guangxi Key Laboratory for Spatial Information and Geometrics (1103108-02).

\section{References}

[1]Deng Julong. Main Method of Gray System. Huazhong University of Science and Industry Press, Wuhan, 2002.

[2]Lu Lijun, Du Zitao. The Use of Grey System Theory in the Deformation Analysis of Building. Geomatics \& Spatial Information Technology 2006; 29(1):95-97.

[3]Dang Yaoguo, Liu Sifeng, Wang Zhengxin, Lin Yi. Study on grey prediction and decision model. Science Press, Beijing, 2009.

[4]Liu Sifeng, Xie Naiming. The Grey System Theory and Its Application. Science Press, Beijing, 2008.

[5]Huang Shengxiang, Yin Hui, Jiang Zheng. Deformation monitoring data processing. Wuhan University press, Wuhan, 2003.

[6]Liu Shu, Wang Yan, Hu Fengge. Study on the Residual Problems of Grey Prediction Model. Statistics and Decision 2008; 1:9-11.

[7]Chen Bo, Wang Jianguo. An Algorithm Analysis of Combination of Gray Linear Regression Model. Journal of Xi, an University of Arts \& Science( Nat Sci Ed) 2012;15(1):82-85.

[8]Li Jie, Zheng Wenxia. Analysis and forecast of gray linear regression model in deformation monitoring data. Guide to Business 2011; 18:234-235.

[9]Xie Naiming, Liu Sifeng. Discrete GM $(1,1)$ and Mechanism of Grey Forecasting Model. Systems Engineering Theory \& Practice 2005; 25(1):93-99.

[10]Wang Fengxiao. Non-equal Time Interval Combination Grey Prediction Model. Mathematics in Practice and Theory 2007; 37(21):39-43.

[11]Chen Jiajia, Chen Weiqing. Building Deformation Analysis Based on the Equal Dimension Dynamic Prediction Model. Surveying and Mapping of Geology and Mineral Resources 2010; 26(4):10-12. 